\title{
NOTAS HISTÓRICAS SOBRE A FAMÍLIA CACTACEAE NO RIO GRANDE DO SUL (BRASIL) E URUGUAI. II - PERÍODO MODERNO (1950-1980): COLECIONADORES E EXPLORADORES DA REGIÃO E IMIGRANTES EUROPEUS ${ }^{1}$
}

\author{
RODRIGO CORRÊA PONTES ${ }^{2}$ \\ JOSÉ NEWTON CARDOSO MARCHIORI ${ }^{3}$ LEOPOLDO WITECK NETO $^{4}$
}

\section{RESUMO}

É abordado o período áureo das descobertas de Cactaceae no Rio Grande do Sul e Uruguai. Muitas espécies novas foram encontradas por entusiastas, sobretudo descendentes de alemães, bem como por imigrantes europeus que percorreram os mais longínquos rincões da região.

Palavras-chave: Botânica, Cactaceae, História, Rio Grande do Sul, Uruguai.

\section{ABSTRACT}

[Historical notes on the Cactaceae family in Rio Grande do Sul (Brazil) and Uruguay. II - Modern period (1950-1980): collectors and explorers from the region and European immigrants]. The golden period of the discoveries about the Cactaceae family in Rio Grande do Sul (Brazil) and Uruguay is analysed. Several new species were found by enthusiasts, mainly from German-Brazilian backgrounds, as well as by European immigrants who crossed the furthest corners of the region.

Key words: Botany, Cactaceae, History, Rio Grande do Sul, Uruguay.

\section{INTRODUÇÃO}

O período da Segunda Guerra Mundial e os anos imediatamente subsequentes foram marcados por notável redução na busca de cactos por coletores estrangeiros, tanto no Rio Grande do Sul como no Uruguai.

No caso do Brasil, a "Campanha de Nacionalização" do governo Vargas passou a interferir desde fins da década de 1930 nas comunidades de imigrantes, vedando o ensino em outras línguas, que não o português, e, até mesmo o uso de língua estrangeira no dia a dia das pessoas.

No Uruguai, além de interromper o afluxo de botânicos estrangeiros, a situação política na

1 Recebido em 20-02-2017 e aceito para publicação em 15-04-2017.

2 Geógrafo, doutorando do Programa de Pós-Graduação em Geografia, Universidade Federal de Santa Maria. rodrigocorreapontes@gmail.com

3 Engenheiro Florestal, Dr. Bolsista de Produtividade em Pesquisa (CNPq - Brasil). Professor Titular do Departamento de Ciências Florestais, Universidade Federal de Santa Maria. marchiori@pq.cnpq.br

4 Engenheiro Florestal, M.e. Professor do Colégio Politécnico, Universidade Federal de Santa Maria. lwiteck@gmail.com
Alemanha motivou o retorno voluntário do botânico Wilhelm Franz Herter (Guillermo Herter) à Europa, após longos anos de atividade no país.

Com o término da Segunda Guerra Mundial, verificou-se, no início da década de cinquenta, um ressurgimento da procura de cactos no Rio Grande do Sul, desta vez a partir de cidadãos gaúchos, sobretudo descendentes de alemães, que começaram a se interessar por essas plantas. Num primeiro momento, a exploração visava, principalmente, a busca de cactos para coleção e fins ornamentais. Mais tarde, devido à influência e parceria de viveiristas europeus, essa busca transformou-se em negócio lucrativo (e competitivo) até o início dos anos oitenta, quando foram implantadas leis ambientais com vistas ao controle e proteção da flora nativa.

Do exposto, conclui-se que o período compreendido entre 1950 e 1980 distingue-se tanto do precedente ${ }^{5}$, marcado pela atuação de botâ-

\footnotetext{
5 Ver: PONTES, R.C.; MARCHIORI, J.N.C.; WITECK NETO, L. Notas históricas sobre a família Cactaceae no Rio Grande do Sul (Brasil) e Uruguai. I - Período
} 
nicos e naturalistas europeus (Figura 1), como do contemporâneo, cujo início decorre da entrada em vigor de leis com vistas à proteção da rica biodiversidade brasileira e ao resguardo dos interesses econômicos a ela associados.

\section{O PERÍODO MODERNO}

Um dos maiores entusiastas por cactos no Rio Grande do Sul entre os anos de 1940 e 1950 foi Carlos Zuckermann, que reuniu uma grande coleção de plantas vivas em Porto Alegre. Das poucas informações sobre sua atividade, sabese que ele também colaborou na construção da primeira casa de vegetação do Jardim Botânico da capital gaúcha, juntamente com o casal Aloysio Pedro Seger (21-09-1896 - 27-031972), natural de Novo Hamburgo, e Dalma Ely Metz Seger (15-09-1900 - 10-06-1983), natural de Estrela Velha. O "cactário", construído, especialmente, para abrigar parte da coleção de plantas suculentas, foi inaugurado em 01-051962 e desativado décadas mais tarde.

Nos anos sessenta, a coleção particular de Zuckermann chegou a reunir cinco mil vasos de cactos e plantas suculentas, aproximadamente, e foi posteriormente incorporada ao acervo do Jardim Botânico de Porto Alegre (Carneiro et al, 2016).

Em 1955, o botânico Wilhelm (Willy) Cullmann (08-06-1905 - 29-01-1992) descreveu Brasilicactus graessneri var. albisetus a partir de exemplares importados pela firma de Hildgart Winter (de Frankfurt) no inverno alemão de 1953-1954, informando, como localidade tipo, "Rio Grande, em Brasil meridional" (Cullmann, 1955), sem qualquer referência ao remetente das plantas para a Europa.

No Rio Grande do Sul, o nome de Rudolfo Heinrich Büneker (10-02-1900 - 23-12-1971) se destaca como pioneiro na busca de cactos. Natural de Corvo, atual município de Colinas, no Vale do Taquari, ele foi o filho caçula dos

Clássico (1818-1950): viajantes naturalistas e botânicos europeus. Balduinia, Santa Maria, n. 56, p. 1-11, 2017. imigrantes alemães Ernst Heinrich Büneker e Catharine Frederike Büneker, oriundos da região de Leeden (Tecklenburg) e que aportaram ao Brasil em 1879. Canteiro, de profissão, Rudolfo Büneker (Figura 2A) construía túmulos com rochas de arenito, ditas "pedra grés". Foi na busca por matéria-prima de boa qualidade que, acidentalmente, deu-se o seu encontro com cactos, evento que marcou o restante de sua vida.

Encontrados em rochas dos morros próximos à sua casa, os cactos foram motivo de curiosidade para Rudolfo, que passou a cultivá-los por sua beleza natural. A busca pela rocha na região entre Corvo e Arroio da Seca (atual município de Imigrante) proporcionou-lhe o primeiro contato com Eriocactus leninghausii. Ainda nas proximidades, ele encontrou, posteriormente, Brasilicactus haselbergii.

Rudolfo admirava-se da existência daquelas plantas de tão rara e exótica beleza em meio a matas densas, e que ali reinavam quase absolutas, acompanhadas, tão somente, por espécies igualmente ousadas.

Por contato com agrimensores alemães que realizavam trabalhos na região de Corvo, Rudolfo iniciou um intercâmbio com Walter Haage, proprietário de tradicional viveiro dedicado ao cultivo de cactos em Erfurt (Alemanha), a quem enviou sementes e plantas em troca de literatura, recebendo, ainda, plantas e sementes para a sua coleção. Rufolfo transmitiu o amor aos cactos para os sobrinhos-netos Leopoldo Horst e Frederico Horst, que também encontraram Eriocactus leninghausii e Brasilicactus haselbergii na natureza, a partir de suas indicações.

A dedicação, paixão e respeito pelas plantas foram também repassados ao filho Rudi Werner Büneker (04-11-1941; Figura 2B), igualmente nascido em Corvo e que, desde a pré-adolescência, o acompanhava em longas caminhadas até os habitats naturais, onde, com o auxílio de grossas cordas de sisal - e sempre com muito esforço e risco -, alcançavam os tão desejados cactos nos paredões rochosos. 


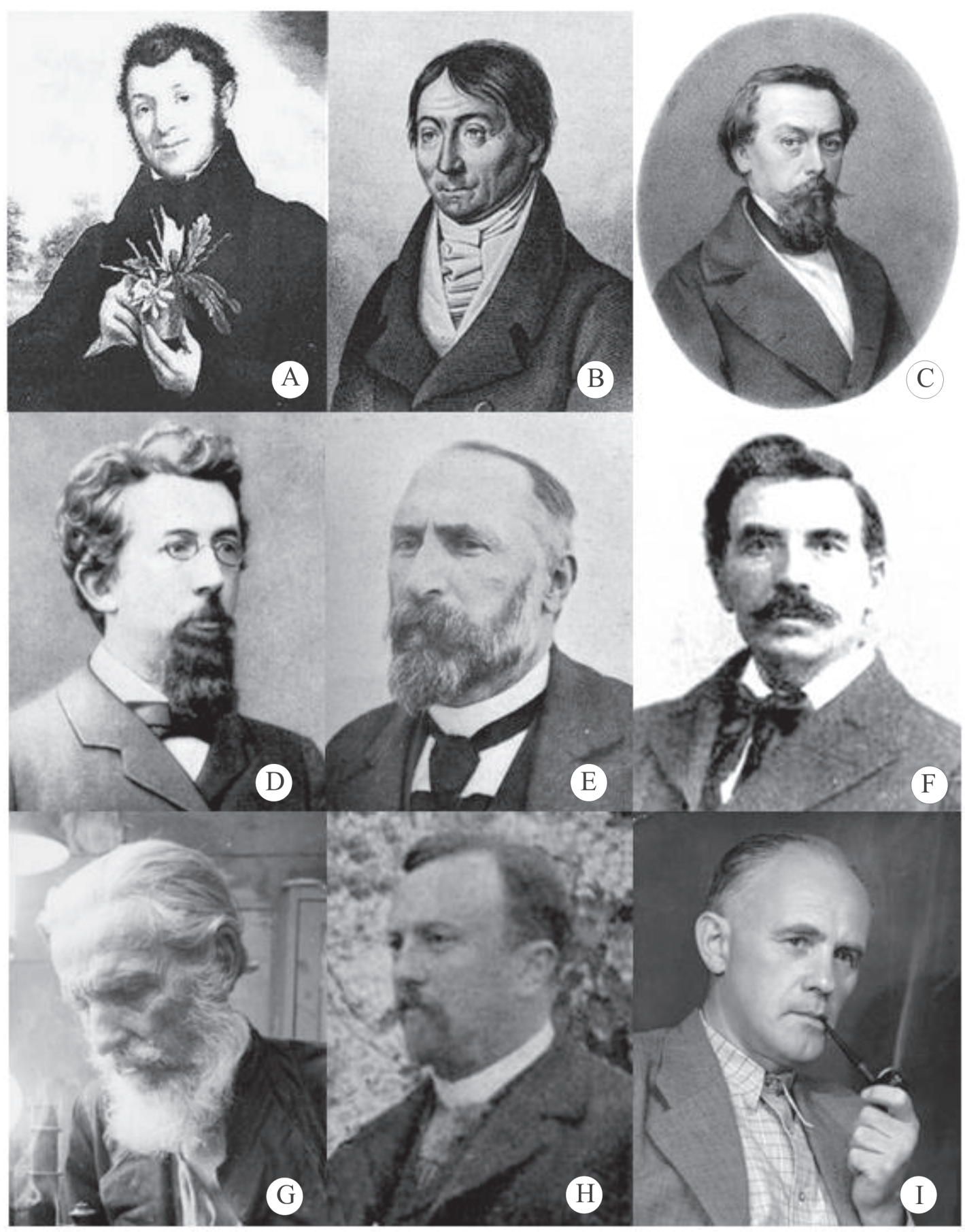

FIGURA 1: Ilustres cactólogos europeus. A - Adrian Haworth. B - Johann Heinrich Friedrich Link. C - Ludwig Pfeiffer. D - Karl Schumann. E - Carlos Spegazzini. F - José Arechavaleta. G - Alberto Friè. H - Cornelius Osten. I - Curt Backberg. 
Apesar das dificuldades financeiras da família, eles sempre mantiveram uma notável coleção de cactos e, ocasionalmente, fotografavam suas plantas em cultivo. A agitação tomava conta de todos quando, na primavera, eram brindados com belas florações. A obtenção de literatura especializada era muito difícil naquela época e, ainda mais, pelas condições financeiras da família -, de modo que foi por correspondência com outros colecionadores, tais como Ernest Vatter (Buenos Aires, Argentina), Albert Buining (Leiden, Holanda), Hans Krainz (Zurique, Suiça), Karl Heinz Uhlig (Kernen im Remstal, Alemanha) e Walter Haage (Erfurt, Alemanha), que puderam obter informações, livros e sementes de cactos. A leitura de textos e o exame das belas fotos de cactos de outros países, incluídas em publicações recebidas, eram momentos prazerosos vivenciados por Rudolfo e seu filho nas horas de descanso, à noite e à luz de lampião.

A primeira excursão de Rudolfo e Rudi fora da região de Corvo deu-se entre setembro e outubro de 1952, quando decidiram empreender uma viagem a mais de duzentos quilômetros de casa. O estímulo surgiu da informação fidedigna de Hugo Osterkamp sobre a existência de cactos nas imediações de Jaquirana, nos Campos de Cima da Serra. Residente em Corvo, o Sr. Osterkamp comercializava guloseimas naquela região e seu encontro com os cactos fora acidental, motivado por problemas mecânicos em seu carro, que saiu da estrada e foi de encontro às rochas.

Sem maiores recursos, Rudolfo e Rudi saíram para a grande viagem com alimentos de casa, suficientes para muitos dias e preparados por Pauline Budke Büneker (20-04-1897 - 2410-1974), bem como com roupas grossas, pois sabiam que as noites eram muito frias naquela região. Até Caxias do Sul, a viagem foi feita em ônibus e sem maiores problemas, apesar de terem levado mais de quatro horas para percorrer os primeiros cem quilômetros. A partir daí, a locomoção foi feita de diversas maneiras, mas, principalmente, de carona em um caminhão madeireiro. Naquela época, o trânsito de caminhões já era intenso na região de Jaquirana, que vivenciava o auge da derrubada das araucárias. Após pernoite em Jaquirana, pai e filho saíram cedo, pela manhã, fazendo os últimos sete quilômetros a pé. Após longa e estafante subida, bem ali, ao lado da estrada, estavam os cactos por eles procurados e que já haviam sido descritos como Brasilicactus graessneri.

Em diversos locais, nas imediações, eles voltaram a encontrar a mesma espécie. Por um morador local, que não entendia o motivo da dupla vir de tão longe por causa daquelas "tunas", tomaram conhecimento da existência de plantas "um pouco diferentes" em local não distante dali.

Devido o adiantado da hora e ao cansaço físico, mas com a curiosidade aguçada pela informação recebida, eles aceitaram o convite do morador para passar a noite em sua casa, na expectativa de boas descobertas no dia seguinte. À noite, degustaram pinhões assados na chapa do fogão à lenha e a conversa foi animada por um bom copo de vinho tinto serrano; embora pré-adolescente, a Rudi também foi permitido alguns goles.

Na manhã seguinte, bem cedo, e poucos quilômetros adiante, encontraram os cactos "diferentes". Rudolfo entusiasmou-se com a planta, por ela ser ainda desconhecida da ciência botânica. A partir desta coleta, foram enviados exemplares para Walter Haage, em 1954, que descreveu a nova espécie como Parodia brevihamata (Haage, 1956).

O retorno para casa, igualmente penoso, foi, em parte, feito a pé, outras vezes de carona, mas nem por isto deixou de ser compensador. No pernoite em Garibaldi, ao pedirem jornais velhos ao hoteleiro (Sr. Leonardo Catto) para embrulhar os cactos colhidos em Jaquirana, ele informou que bem perto dali havia plantas semelhantes. No dia seguinte, bem cedo, já estavam no local, junto aos cactos, e mais uma vez tiveram a felicidade de encontrar uma planta 
cientificamente desconhecida, a qual foi posteriormente descrita como Notocactus linkii var. buenekeri (Ritter, 1979).

No ano de 1957, Rudolfo decidiu visitar a Alemanha, levando, em sua mala, muitas sementes de Brasilicactus haselbergii e Eriocactus leninghausii, oportunidade que lhe serviu para contatos com outros colecionadores de cactos e viveiristas. Os valores obtidos pela venda das sementes garantiram sua passagem de volta ao Brasil.

No início dos anos sessenta, em viagem aos Aparados da Serra, feita em companhia do sobrinho-neto Leopoldo Horst, Rudolfo encontrou Parodia buenekeri na região da Rocinha, município de São José dos Ausentes (Buining, 1962). As incursões prosseguiram nas imediações, onde novos achados foram, paulatinamente, realizados.

Em fins de 1964, Rudolfo comprou seu primeiro veículo, uma Kombi branca e vermelha, e no segundo semestre de 1965 realizou a primeira viagem com Rudi e Leopoldo Horst, seu sobrinho-neto. Ocorre que novas informações sobre ocorrência de cactos, recebidas de vizinhos, amigos ou simples conhecidos, estimulavam a realização de viagens.

Bruno Lawrens, um amigo da família Büneker e que era engenheiro eletricista da empresa H. Würz (de Estrela, RS), contou que na instalação das turbinas da Usina de Cafundó, em Nova Palma, ele observou cactos em paredões rochosos. Apesar da curiosidade, Büneker e Horst não puderam averiguar a informação in loco, naquele momento. Mais tarde, em 1965, Leopoldo Horst esteve no local com Friedrich Ritter, e coletaram material para o holótipo de Eriocactus claviceps.

História similar ocorreu com a descoberta de Eriocactus magnificus. Por intermédio de uma vizinha, a Sra. Loni Klein Fuchs, esposa de Erno Fuchs, estabelecido com casa de comércio na Linha Ano Bom, em Corvo, Rudolfo tomou conhecimento da existência de cactos em paredes rochosas da usina de Quebra Dentes, no Rio Toropi, conhecida pelo casal no início dos anos sessenta, por ocasião de visita a um irmão de Erno, residente em São Pedro do Sul. Em 1965, Rudolfo, juntamente com Leopoldo Horst e Friedrich Ritter foram a esse local, registrando a população em conhecida foto publicada em livro, por Ritter (1979).

Também por contatos, Rudolfo tomou conhecimento da existência em Santa Cruz do Sul de exemplares de um novo Eriocactus, com 15-16 costelas. A investigação mostrou que o fornecedor das plantas era um ferreiro de nome Grunewald, que morava próximo à subida de Trombudo, no vale do Rio Pardo. Na ocasião da visita, o ferreiro já havia falecido, de modo que o habitat natural daquela novidade seguiu desconhecido. Mais tarde, apesar da intensa pesquisa de campo realizada por Büneker, Horst e Ritter, o habitat natural desse cacto não foi encontrado (Ritter, 1979).

Em 1965, Rudolfo e Rudi exploraram Candelária, Santa Maria, Itaara, São Pedro do Sul, Toropi e Quevedos. Em viagens posteriores, foram explorados os municípios de Alegrete, Bagé, Caçapava do Sul, Dom Pedrito, Lavras do Sul, Manoel Viana, Não Me Toque, Panambi, Quaraí, São Francisco de Assis, São Gabriel, Santana do Livramento e Uruguaiana.

Entre setembro e dezembro de 1965, Rudolfo e Rudi foram a São Francisco de Assis em busca de uma espécie ainda desconhecida e que, mais tarde, seria descrita como Notocactus fuscus. Ao encontrar um pequeno morro rochoso, Rudolfo decidiu seguir com sua Kombi o mais próximo possível. Ao descer do carro, após alguns passos, ele encontrou um novo cacto, descrito, posteriormente, como Gymnocalycium horstii var. buenekeri (Buining 1970, Swales, 1978).

Em 1967, Büneker e Rudi descobriram um novo cacto na região de Caxias do Sul. Esse achado chamou a atenção de Leopoldo Horst, que, na época, estava acompanhado pelo taxonomista holandês Albert Frederik Hendrik Buining (25-08-1901 - 09-05-1976), natural de Groningen. Em 10-02-1967, dia do aniversário de sessenta e sete anos de Rudolfo, Buining e Horst o visitaram, pedindo-lhe para mostrar o 
habitat da novidade. Rudolfo e Rudi os levaram ao local, onde foram realizadas fotos e coletado material botânico. Em 1968, na revista alemã "Kakteen und andere Sukulenten" foi publicada a descrição de Notocactus rechensis, atribuindo a descoberta a Rudolfo Büneker.

Outra planta interessante, descoberta ao final dos anos sessenta, foi Notocactus dalvae, encontrada por Dalva Lovaina Büneker (Forquetinha, 08-04-1947), esposa e companheira de viagens de Rudi Büneker. Como não foram realizadas fotografias no habitat natural, não se sabe se havia um "pequeno agrupamento de meia dúzia de plantas ou, apenas, uma planta com meia dúzia de brotos" (Büneker, comunicação pessoal). Posteriormente, Friedrich Ritter considerou o binômio nomen nudum e apenas o mencionou na lista de números de campo (Ritter, 1981, p. 1648).

Em 1971, Rudolf e Rudi voltaram a realizar, sem sucesso, mais uma viagem em busca do Eriocactus com 15-16 costelas, e que crescia em paredões no vale do Rio Pardo (Ritter, 1973). Nesse mesmo ano, Rudolfo faleceu em razão de complicações cardíacas, que se acentuaram em 1969 por intoxicação com agrotóxicos aplicados em sua coleção de cactos.

Em outubro de 1972, Rudi Büneker e seu primo Rucart Egon Horst (12-12-1952), nascido na Linha Ano Bom, em Corvo (atual Colinas), localizaram o habitat do visado Eriocactus do vale do Rio Pardo: situava-se apenas três quilômetros além do ponto alcançado na primeira viagem, realizada com seu pai. A espécie foi descrita como Eriocactus warasii, em homenagem ao dinamarquês Eddie Waras (12-03-1918 - 1708-1995), nascido em Frederiksberg (Copenhague), e patrocinador de seus trabalhos de campo (Ritter, 1973).

Muito pouco se pode apurar sobre Waras (Figura 2C). Sua primeira vinda ao Brasil foi em 1950; por alguns anos morou com a família em São Paulo, depois retornou à Dinamarca, e voltou ao Brasil na década de sessenta. Entre 1968 e 1978, Eddie Waras se estabeleceu em
São Paulo, onde manteve um viveiro especializado na propagação e comércio de bromélias e orquídeas. Na época, devido ao pouco interesse dos brasileiros por essas plantas, ele mudou o foco de seu negócio, passando a dedicarse à reprodução e venda de cactos nativos (Kalmbacher, 1971).

De 1971 a 1978, Eddie financiou e acompanhou Rudi Werner Büneker em diversas viagens. Rudi, por sua vez, passou a fornecer plantas e sementes, que eram cultivadas em São Paulo, depois enviadas para estufas na Dinamarca e, finalmente, distribuídas para viveiros da Europa.

Na primeira metade dos anos setenta foram descobertas Notocactus rudibuenekeri e Frailea buenekeri, ambas descritas mais tarde (Abraham, 1988, 1990). Por convicções próprias, Rudi abandonou o comércio de plantas em 1989, mas deu seguimento ao legado de seu pai, auxiliando a pesquisadores em trabalhos de campo e na taxonomia de cactáceas.

Em sua luta pela conservação e preservação dos cactos, Rudi realizou um marco na conservação "in situ", ao encaminhar o processo da criação da Reserva Biológica Rudolfo Henrique Büneker, instituída pelo decreto municipal $\mathrm{n}^{\circ}$ $2.185 / 95$, de 23 de outubro de 1995, na cidade de Garibaldi (RS), criada, especialmente para proteger uma população próxima à populaçãotipo de Notocactus linkii var. buenekeri (Abraham, 1996). Naturalista por vocação, Rudi vivencia uma avançada concepção filosófica e evolucionista sobre o mundo e as diversas formas de vida.

No Rio Grande do Sul (e no Brasil), a maior autoridade em cactos foi, indubitavelmente, Leopoldo Horst (16-02-1918 - 03-02-1987). Nascido na localidade da Linha Ano Bom, em Corvo (atualmente município de Colinas), Leopoldo Horst (Figura 2D) era filho de imigrantes alemães da região de Tecklenburg e, desde cedo, trabalhava com seus pais nos afazeres rurais (Braun, 1983; Herm et al. 2000). Por essa razão não pôde concluir os estudos, 
até mesmo porque a escola mais próxima ficava distante de casa.

Por influência de Rudolfo Henrique Büneker, seu tio-avô, Leopoldo Horst, já na adolescência, apreciava a natureza, cultivava cactos e orquídeas, e gostava de andar pelas florestas e morros próximos a sua casa, em busca de plantas com belas flores (Herm et al. 2000; Bergesh et Bersch, 2012). A realidade, entretanto, se impunha: era preciso trabalhar na roça, mesmo que contrariado, pois essa era sua fonte de sobrevivência.

Junto com o tio-avô Büneker e seu irmão Frederico Horst Filho (12-05-1924 - 06-072002), exploraram os morros da região de Corvo, onde teve seu primeiro contato com cactos no ambiente natural, em escarpas rochosas onde cresciam Brasilicactus haselbergii e Eriocactus leninghausii (Braun, 1983). Gradativamente, começou a criar uma coleção de cactos, o que, de certa forma, era uma preferência estranha aos amigos e vizinhos.

Outro interesse de Leopoldo era a eletricidade. Com apenas 18 anos, ele criou um gerador hidráulico de energia elétrica, dito "Elektrisch Horst", para uso nos cursos de água da região (Herm et al. 2000). Com a notoriedade adquirida, trabalhou como eletricista nos municípios de Arroio do Meio, Estrela, Lajeado, Roca Sales e Teutônia.

Após os trinta anos de idade, adquiriu uma pequena área de terra, de onde passou a obter o sustento, e em 1943 casou-se com Melita Brune Horst (04-02-1916 - 26-12-2012). Leopoldo também trabalhou como apicultor e fotógrafo de eventos. Enquanto estava em serviço, sua esposa trabalhava na roça e como costureira, para sustentar os filhos Gundela, Gernot Gundolf e Kurt Ingo (Bergesh et Bersch, 2012).

Horst era atraído por desafios: ele foi o primeiro a dirigir um automóvel em Arroio da Seca e também o responsável pela construção de uma rede de energia elétrica de $30 \mathrm{~km}$, entre a cidade de Estrela e Arroio da Seca (Herm et al. 2000). Como a produção do minifúndio não rendia o suficiente, decidiu vendê-lo e mudar-se com a família para a vila de Arroio da Seca (atual Imigrante), levando consigo a sua amada coleção de cactos.

Nessa nova etapa da vida, Leopoldo entrou como sócio em uma marcenaria. O ofício, entretanto, serviu-lhe por pouco tempo, pois um incêndio consumiu o investimento realizado com tanto esforço (Bergesh et Bersch, 2012). Em seguida, ele aceitou um convite para vender rifas em benefício do tradicional Colégio Martin Luther, de Estrela, que pretendia construir um educandário. O prêmio - um automóvel zero quilômetro, e que serviu para os deslocamentos na venda da rifa -, deu-lhe a oportunidade de buscar cactos em locais ainda não visitados, nas horas de folga. Nessas viagens, Leopoldo percorreu os municípios de Estrela, Lajeado, Venâncio Aires, Santa Cruz do Sul, Trombudo (atual Vale do Sol), Candelária, Agudo e Santa Maria, encontrando, ao mesmo tempo, outras espécies de cactos para sua coleção.

Por sua notoriedade com cactos, o pastor Heinrich Brakemeier ${ }^{6}$ (09-03-1909 - 16-011986), que tinha muitos contatos nas Alemanhas Ocidental e Oriental, contou a Leopoldo Horst sobre o recebimento de cartas de europeus interessados em cactos nativos do Brasil, com o que muito o ajudou a firmar-se no comércio de plantas e sementes. O pastor também lhe mostrou um livro sobre a importância dos cactos e as belas espécies até então descritas no Rio Grande do Sul.

É importante lembrar que Horst já havia remetido plantas para colecionadores após o término da Segunda Guerra Mundial, como Walther Haage (de Erfurt, Alemanha), mediante informação de seu tio-avô, Rudolfo Henrique Büneker (Uebelmann, 1996). Leopoldo também já havia acompanhado Friedrich Ritter em algumas viagens nos anos de 1964 e 1965, amadurecendo a idéia de buscar o sustento pelo cultivo e comércio de plantas. As descobertas de

\footnotetext{
6 Heinrich Brakemeyer foi pastor da paróquia de Arroio da Seca de 1952 a 1964.
} 
Horst e do famoso botânico, nesse período, foram posteriormente publicadas no periódico holandês "Succulenta" (Ritter 1966, 1970) e no livro "Kakteen in Südamerika" (Ritter, 1979).

Ao atender a recomendação do pastor Brakemeier de escolher plantas de sua coleção para enviar à Europa, um dos primeiros contatos de Horst foi Werner J. Uebelmann (16-031921 -01-03-2014), renomado colecionador de cactos e suculentas, nascido em Aarau (Aargau, Suíça). Membro da Sociedade Suíça de Cactos aos 27 anos de idade (Herm et al, 2000), Uebelmann (Figura 2F) transferiu-se com a família para a região campestre de Wohlem (Suíça) em 1964, onde, com sua esposa Rösli, fundou a "Su-Ka-Flor", um empreendimento de jardinagem, especializado em cactos ornamentais e no fornecimento de plantas da América do Sul.

Na Europa, o cultivo de cactos por amadores crescera consideravelmente após a aparição de Uebelmann em um programa de televisão sobre o tema, na Alemanha (Uebelmann, 1996). Naquele momento, Uebelmann já tinha alguns fornecedores de plantas e sementes na Argentina, Chile e Peru, mas nenhum no Brasil (Uebelmann, 1996). O primeiro pacote enviado por Horst, com cinqüenta plantas, surpreendeu Uebelmann, pois quarenta e oito delas eram novidades ou plantas desconhecidas na Europa (Herm et al., 2000).

Desde o início, Horst pôs Uebelmann a par dos contatos anteriores de seu tio-avô Rudolfo Büneker com Walther Haage, na Alemanha, e Albert Buining, na Holanda (Braun, 1983). O próprio Uebelmann já sabia disso, pois vendia sementes a Haage, que o tinha comunicado sobre um novo contato no sul do Brasil (Uebelmann, 1996).

Após o envio das primeiras plantas, foi firmado um contrato comercial em tabelionato, com cláusulas para regulamentar as atividades e relações entre ambas as partes. Horst devia garantir o fornecimento exclusivo das plantas para Uebelmann, recebendo, em contraparte, a garantia de lucro e a cobertura das despesas das expedições. Também, pelo contrato, todas as novidades a serem descobertas deveriam receber tratamento taxonômico de Albert Buining (Figura 2E), o renomado taxonomista holandês (Uebelmann, 1996).

Mais tarde, também ficou acertado o pagamento de um valor para cada nova espécie descoberta, mesmo que já tivesse recebido uma descrição formal. As plantas seriam numeradas pelo acrônimo HU (Horst-Uebelmann) e, pelo combinado entre Uebelmann, Horst e Buining, o primeiro deles teria a primazia de viajar com Horst (Uebelmann, 1996).

Por razões desconhecidas, Buining não honrou o trato, solicitou férias na Holanda e veio para o Rio Grande do Sul, onde viajou de 0111-1966 até 20-11-1966 e de 09-01-1967 até 3001-1967, oportunidades em que visitou, inclusive, o Uruguai. Horst o acompanhou em sua velha Rural Willys Ford azul (ano 1946), com mais de 400 mil quilômetros rodados.

Essas violações contratuais geraram atritos e tensões no grupo. Ainda em 1966, com o contrato em vigor e boa parte do Rio Grande do Sul explorada, Leopoldo decidiu por uma empreitada maior e começou a viajar, pela primeira vez, a outros estados do Brasil, com o amigo e professor Dr. Gastão Baumhardt (07-03-1925 01-04-1970), natural de Santa Cruz do Sul e colecionador de orquídeas (Uebelmann, 1996).

$\mathrm{O}$ acordo foi tão positivo que as plantas, reunidas no Rio Grande do Sul, eram remetidas de Porto Alegre para a Suíça, inicialmente de navio e mais tarde de avião. De lá, as novidades eram comercializadas em grandes mercados, bem como para colecionadores particulares e jardins botânicos da Europa. Desta forma, a empresa cresceu e adquiriu notoriedade internacional. Horst e Buining viajaram de 26-081968 a 08-10-1968, no Rio Grande do Sul e Uruguai, e em três períodos, pelo interior do Rio Grande do Sul: de 14-05-1972 a 22-05-1972; de 12-09-1972 a 22-09-1972; e de 02-10-1972 a 18-10-1972.

Buining descreveu algumas espécies novas do Rio Grande do Sul e norte do Uruguai. Em 1968, foram descritas: Notocactus uebel- 
mannianus, $N$. uebelmannianus var. flaviflorus e $N$. rechensis (Buining, 1968). Em viagens com Horst, Buining encontrou Notocactus buiningii, descrita em sua homenagem pelo botânico austríaco Franz Buxbaum (25-02-1900 - 07-021979) (Buxbaum, 1968).

No início da década de setenta, foram descritos Gymnocalycium horstii, G. horstii var. buenekeri (Buining, 1970), e Notocactus pseudoherteri (Buining, 1971). Na sequência, foram descritos: Frailea curvispina, $F$. mammifera e Notocactus oxycostatus (em 1972); Frailea albiareolata, F. deminuta e $F$. lepida (em 1973); e Notocactus multicostatus (em 1974), por Buining, em parceria com Arnold J. "Nol" Brederoo (1917-1999), na obra "Die Kakteen", de Hans Krainz, publicada em folhetos periódicos entre 1966 e 1975. Outras espécies descritas foram: Frailea fulviseta (Buining, 1973), F. aureinitens (Buining et Brederoo, 1976) e Notocactus linkii var. flavispinus (Brederoo et Theunissen, 1978). Buining faleceu precocemente, em decorrência de intoxicação aguda por pesticidas aplicados nas plantas de sua estufa particular.

Horst e Uebelmann ainda realizaram longas viagens pelo Rio Grande do Sul nos anos de 1967, 1968, 1970, 1972, 1974 e 1978 (Braun, 1983). Em 1982, Uebelmann vendeu seu negócio e, junto com sua esposa, viajou para o Brasil, onde passou três meses. Em 1985, Horst e Uebelmann realizaram uma última viagem, com duração de quatro meses, percorrendo o Brasil de norte a sul (Uebelmann, 1996).

Até o fim da vida, Horst descobriu novas populações (e espécies) de cactos no Rio Grande do Sul e viajou para outros estados do Brasil e para países vizinhos, como Argentina, Bolívia, Paraguai e Uruguai, sempre em busca de cactos (Braun, 1983; Herm et al. 2000).

Pouco antes do seu falecimento em Arroio da Seca, Horst ainda organizou excursões para estrangeiros interessados em conhecer e fotografar os habitats naturais de cactos.

Resta salientar que é ao trabalho de Leopoldo Horst que se deve o conhecimento científico de diversas espécies de cactos do Rio Grande do Sul e Uruguai, bem como sua difusão internacional. Seu nome, por fim, certamente haverá de perdurar entre os maiores prospectores de cactos do mundo. Após sua morte, o filho Kurt Ingo Horst (21-06-1959) deu continuidade a seu trabalho e negócio, excursionando com estrangeiros, como Uebelmann, Hofacker e Herm, pelo Rio Grande do Sul e Uruguai (Herm, 1990).

Outra grande personalidade no mundo dos cactos foi Friedrich Ritter (09-05-1898 - 09-041989). Natural de Quentel, Bad Hersfeld (Alemanha), Friedrich Ritter (Figura 2G) estudou seis semestres de Biologia, Geologia e Paleontologia na Universidade de Marburg, Alemanha (Ritter, 1964). Na década de 1920, imigrou com a família para o México, tendo seu primeiro contato com cactos em 1928. Até 1937, explorou diversas regiões do México, coletando sementes e plantas a pedido de colecionadores e viveiristas da Alemanha, tarefa que se converteu em sua principal fonte de sustento (Herm et al, 2000; Ritter, 1977).

De 1937 a 1952, Ritter viveu em Berlim, Tübingen e Baden-Baden (Floresta Negra), e serviu ao exército alemão na França e Itália, ao final da Segunda Guerra Mundial (Ritter, 1964). Com o término da guerra, atravessou os Alpes a pé (e por estradas secundárias), da Itália à Alemanha, aonde já chegou sem posses. Para retomar a vida, decidiu coletar plantas e sementes de cactos, passando, mais tarde, a elaborar descrições taxonômicas de seus próprios achados.

Em 07-12-1952, Ritter partiu de Marselha (França) para a América do Sul e chegou ao Rio de Janeiro em 18-12-1952, dando início a coletas documentadas (Ritter, 1977). As datas de suas visitas ao Rio Grande do Sul são descontínuas, pois ele se deslocava de um local para outro sem permanecer muito tempo em uma mesma região.

No Rio Grande do Sul, suas primeiras viagens foram a Canela (19-04-1959), à região entre Taquara e Porto Alegre (21-04-1959), a Gloria (Porto Alegre, 21-04-1959), novamente entre Porto Alegre e Taquara (23-04-1959), leste 
de Esteio (24-04-1959), Ponta Grossa (sul de Porto Alegre, sem data precisa, mas, possivelmente, em 25-04-1959), leste de Porto Alegre (26-04-1959) e, novamente, a Ponta Grossa, ao sul de Porto Alegre (29-04-1959) (Eggli et al., 1995).

Ao término dessa primeira incursão ao estado gaúcho, Ritter saiu de Porto Alegre, provavelmente em 29-04-1959, passando por Guaíba, Vasconcelos $^{7}$, Tapes, Camaquã, São Lourenço do Sul, Pelotas, Rio Grande, Pinheiro Machado e Bagé (30-04-1959). Nas sequência, passou pelas estações de Parada Saibro ${ }^{8}$, Itapevi ${ }^{9}$, Jacaquá, Tigre, Inhanduí ${ }^{10}$, chegando até Monte Caseros (Corrientes, Argentina) em 03-051959.

No ano de 1964, Ritter realizou diversas coletas com Leopoldo Horst e, algumas vezes, com Rudolfo Büneker, nas seguintes localidades: Glória (Porto Alegre, 25-02-1964), Porto Alegre (27-02-1964), Corvo (28-02-1964), Itapuã (Viamão, 03-03-1964), São Jerônimo e Arroio dos Ratos (05-03-1964), Arroio da Seca e Daltro Filho (08-03-1964), Berlim ${ }^{11}$ (09-03-1964), Garibaldi (11-03-1964), Vila Jansen (Farroupilha, 11 e 12-03-1964), Arroio da Seca (15-03-1964), Estrela e Corvo ${ }^{12}$ (16-03-1964), Cerro Botucaraí (Candelária do Sul, 17-031964), Cerro Agudo (Agudo, 18-03-1964), Vinte Tiros e Toropi (19-03-1964), Toropi (21-031964), Loreto (São Vicente do Sul) e Jaguari (22-03-1964), Jaguari, Morro Tavari (Taquarichim, Jaguari) e Sanga da Areia, na estrada de

7 Vila Vasconcelos, antigo nome da atual cidade de Sentinela do Sul, na microrregião de Camaquã.

8 Também dita "Saibro", estação da linha ferroviária Cacequi-Marítima (km 788,222), no município de Dom Pedrito, a $306 \mathrm{~m}$ de altitude, inaugurada em 01-11-1938.

9 Estação ferroviária na linha Porto Alegre-Uruguaiana (km 660,531), no município de Cacequi.

${ }^{10}$ Jacaquá, Tigre e Inhanduí são estações ferroviárias da linha Porto Alegre-Uruguaiana, no município de Alegrete; as duas primeiras, situam-se na parte leste do município, e a última, a oeste da cidade.

${ }^{11}$ Nome de linha colonial, no atual município de Imigrante.

12 Antigo nome da atual cidade de Colinas, na microrregião Lajeado-Estrela.
Jaguari para Santiago (23-03-1964), Santa Maria (24-03-1964), Corvo (25-03-1964), Porto Alegre (26-03-1964) e Guaíba (27-03-1964) (Eggli et al., 1995).

Em 1965, novamente com Horst e Büneker, investigaram nos seguintes locais: Guaíba (0602-1965); Itapuã (Viamão, 07-02-1965); Porto Alegre (08-02-1965); Arroio dos Ratos (09-021965); Encruzilhada do Sul (10-02-1965); Porto Alegre (11, 12 e 13-02-1965); Pareci Novo (14-02-1965); Montenegro (15-02-1965); Arroio da Seca (17-02-1965); Arroio da Seca (2202-1965); Pantano Grande e Rincão do Segredo $^{13}$ (24-02-1965); Guaritas (Caçapava do Sul, 25-02-1965); Minas do Camaquã (Caçapava do Sul) e oeste de Santana da Boa Vista (26-021965); oeste de Santana da Boa Vista, em direção à Caçapava do Sul, entre Caçapava do Sul e Lavras do Sul, e Mina Seival, ao sul de Caçapava (27-02-1965); Ibaré , em direção a Bagé e Lavras do Sul, e em direção a Bagé (28-02-1965); Ibaré (01-03-1965); Toropi (02-03-1965); Julio de Castilhos (04-03-1965); Arroio da Seca (dias 8 e 9-03-1965); Arroio da Seca (13-03-1965); Corvo (15-03-1965); Rio da Várzea e Usina Mata Cobra (norte de Carazinho, 19-03-1965); Julio de Castilhos, Quevedos e Usina São Pedro $^{14}$ (20-03-1965); sul de Quevedos, em direção a Toropi, e Cerro Itaquatiá, em São Pedro do Sul (21-03-1965); leste de Taquarichim (2203-1965); Barragem Furnas do Segredo, em Jaguari (23-3-1965); Sanga da Areia (Jaguari) e sul do município de Santiago (24-03-1965); Cerro Chato e Cerro Branco, no sudoeste de Santiago (25-03-1965); região entre São Francisco de Assis e Santiago, oeste de São Francisco de Assis, em direção a Alegrete, Jacaquá e sudoeste de São Francisco de Assis (26-031965); oeste de Alegrete e sudoeste de Harmonia, em direção a Quaraí (27-03-1965); oeste e norte de Quaraí, e Cerro do Jarau (29-03-1965); Quaraí, rumo a Passo da Guarda e sul de Passo

\footnotetext{
${ }^{13}$ Mais conhecida como Pedra do Segredo

${ }^{14}$ No município de Quevedos.
} 
da Guarda, em direção a Santana do Livramento (30-03-1965); Santana do Livramento (3103-1965); Rivera e Santana do Livramento, na divisa Brasil-Uruguai, e Cerro Palomas, em Santana do Livramento (01-04-1965); e Chamberlain ${ }^{15}$, no Uruguai (06-04-1965) (Eggli et al., 1995).

Sem datas precisas, ainda existem coletas em localidades como: Rio Pelotas (Bom Jesus), Fortaleza $^{16}$ (Cambará do Sul), Serraria Scheidt (município de Cerro Branco), Campestre Alto (São Pedro da Serra), Jaquirana, Serrinha (Roca Sales), Cazuza Ferreira e Tainhas (São Francisco de Paula), Três Pontes (Soledade) e Vacaria.

Outros registros indicam: Berlim (Imigrante, 1967), São Gabriel (1968), Ana Rech (1969), São Gabriel e Ibaré (1970). Sobre os mesmos, entretanto, acredita-se que não correspondam a expedições suas, mas a material remetido por Horst e Büneker.

Resta salientar que algumas plantas descritas por Ritter foram obtidas das coleções particulares de Horst e Büneker, pois é bem provável que ele não tenha visitado alguns habitats.

Em 1966, Ritter publicou novidades, como Eriocactus claviceps, E. magnificus e Notocactus horstii, espécies que fomentaram, ainda mais, o prestígio dos cactos sul-americanos entre os colecionadores europeus (Ritter, 1966). Em 1970, Ritter descreveu Notocactus arachnites, $N$. arachnites var. minor, $N$. crassigibbus, $N$. purpureus, $N$. succineus e $N$. tenuicylindricus (Ritter, 1970).

Após as viagens ao Brasil, Ritter retornou para casa, em Valparaíso (Chile), e mais tarde se estabeleceu no Paraguai. Em 1976, por razões políticas, retornou à Europa, passando a viver com sua irmã em Spangenberg (Alemanha). Durante esse tempo, dedicou-se à organização de sua obra prima, intitulada "Kakteen in Südamerika", financiada e editada com recursos próprios, entre 1979-1981 (Wittau, 1982;

${ }^{15}$ Localidade do departamento uruguaio de Taquarembó, situada $15 \mathrm{~km}$ ao norte da cidade de Paso de los Toros.

${ }^{16}$ Nome de conhecido cânion, nos Aparados da Serra.
Herm et al, 2000), e que apresenta resultados de vinte anos de trabalhos de campo na América do Sul.

No primeiro volume, dedicado, exclusivamente, a espécies do Brasil, Paraguai e Uruguai, Ritter descreveu diversas espécies novas, variedades e formas botânicas para o Rio Grande do Sul: Brasiliparodia buenekeri var. conjugens, $B$. buenekeri fa. intermedia, B. brevihamata var. mollispina, B. brevihamata fa. conjungens, $B$. catarinensis, Eriocactus leninghausii var. minor, Frailea albifusca, F. albicolunaris, F. asperispina, F. asterioides var. harmoniana, $F$. aureispina, F. aureispina var. pallidior, F. horstii, F. perumbilicata, F. perumbilicata var. spinosior, F. pygmaea var. altigibbera, F. pygmaea var. curvispina, F. pygmaea var. lilalunula, $F$. pygmaea var. longispina, $F$. pygmaea var. major, F. pygmaea var. planicosta, F. pumila var. major, Notocactus arechavaletae var. aureus, $N$. arechavaletae var. alacriportanus, $N$. arechavaletae var. aureus, $N$. arechavaletae var. buenekeri, $N$. arechavaletae var. horstii, $N$. arechavaletae var. limiticola, $N$. arechavaletae var. nanus, $N$. arechavaletae var. rubescens, $N$. acutus, $N$. campestrensis, $N$. cristatoides, $N$. curvispinus, $N$. eremiticus, $N$. fuscus, $N$. fuscus var. longispinus, $N$. glaucinus, $N$. glaucinus var. depressus, N. glaucinus var. gracilis, $N$. globularis, $N$. horstii var. purpureiflorus, $N$. harmonianus, $N$. laetvirens, $N$. linkii var. buenekeri, $N$. linkii var. guaibensis, $N$. neobuenekeri, $N$. ottonis var. acutangularis, $N$. permutatus, $N$. rubropedatus, $N$. securituberculatus, $N$. securituberculatus var. miniatispinus, $N$. spinibarbis, N. megapotamicus var. crucicentrus, N. megapotamicus var. horstii, N. megapotamicus var. vulgatus, Piptantocereus bageanus, Platyopuntia brunneogemmia, $P$. rubrogemmia, $P$. viridirubra, Rhipsalis clavelina, R. alboareolata, R. flosculosa, Wigginsia leprosorum, W. longispina, W. prolifera, W. horstii e W. horstii var. juvenaliformis (Ritter, 1979).

Além da descrição taxonômica das espécies, a obra de Ritter fornece comentários, obser- 
vações, dados detalhados e fotografias das plantas, além de propor novas combinações e novos gêneros, como Brasiliparodia. Outro ponto relevante, em sua obra, é o espírito crítico à concepção de outros taxonomistas contemporâneos.

Em 1982, Ritter doou seus diários, documentos e a coleção de sementes para sociedades européias dedicadas aos cactos, mudou-se para Puerto de La Cruz, na ilha de Tenerife, Canárias (Herm et al, 2000), falecendo em 1989 (Müller, 1989).

Seu extenso (e meticuloso) trabalho converteu-o num dos grandes, senão o maior pesquisador da família Cactaceae para o Rio Grande do Sul, pois tanto aprofundou o conhecimento das espécies nativas no estado, como contribuiu para a preservação das mesmas mediante cultivo, na Europa.

No Uruguai, o grande expoente na prospecção de cactos no período em foco foi Hugo Selmar Schlosser (06-12-1903 - 13-011987). Nascido na Áustria - e de pais judeus -, Schlosser (Figura 2H) imigrou ainda na infância para a Alemanha, com sua família. Sempre interessado em jardinagem, em 1933 foi nomeado Inspetor de Horticultura, credenciado pelo estado de Berlim-Dahlem, e passou a desempenhar atividades nesse setor (Herm, 1987). Em 1938, durante a "Noite dos Cristais", ele foi preso pelos nazistas e separado de sua família. Libertado, posteriormente, com a condição de deixar a Alemanha no prazo de um mês, Hugo conseguiu sair da Europa através da França, e embarcou para a Argentina. Devido a erro de um oficial, Hugo e sua família desembarcaram em Montevidéu (Uruguai), mas a mobília seguiu para Buenos Aires, Argentina (Abraham, 1984).

Os primeiros anos foram muito difíceis, devido à falta de recursos, até se estabelecer na capital uruguaia. Na sequência, ele aceitou a oferta para administrar uma fazenda na província de Tucumán (Argentina). Findo esse período de labor agrícola, retornou a Montevidéu e adquiriu uma chácara, onde estabeleceu o viveiro "La Ardillita", para o cultivo e comércio de plantas ornamentais, arbóreas, frutíferas e espécies ainda pouco conhecidas no Uruguai e Brasil. Outro empreendimento, por ele desenvolvido - e de nome "Lumo" -, destinava-se a trabalhos fotográficos, fotocópias, microfilmes e revelações (Abraham, 1984).

Seu interesse pelos cactos foi despertado em 1964 pela leitura de obras sobre as espécies nativas do Uruguai. Através de pesquisa, ele verificou que se sabia muito pouco dos cactos uruguaios e, sobretudo, dos locais de ocorrência das espécies nativas, principalmente dos gêneros Echinopsis, Frailea, Gymnocalycium e Notocactus (Abraham, 1984; Herm, 1987). Na sequência, passou a excursionar por todo o país em busca de cactos, atividade que exerceu até o fim da vida.

Seu grande conhecimento sobre espécies uruguaias o converteu em uma das maiores autoridades sobre cactos no país. Essa notoriedade atraiu pesquisadores europeus, como Dirk van Vliet (Figura 2I) e Walter Rausch, que o visitaram em Montevideo antes de começarem suas buscas pelo interior do Uruguai (Abraham, 1984; Theunissen, 2004, 2014).

Nas excursões, Hugo Schlosser encontrou belas plantas. Alguns dos primeiros achados foram descritos por van Vliet como Notocactus blaauwianus e Notocactus schlosseri; este, em homenagem a Hugo e ao seu filho Peter, que o acompanhava nas viagens, sempre que possível (Gerloff et. al 2004).

Hugo também descreveu Notocactus roseiflorus (encontrado em 12-12-1970), $N$. paulus (fevereiro de 1972), N. megalanthus (1910-1975), N. ferrugineus (14-12-1976) e $N$. erythracanthus, sendo algumas delas em parceria com o botânico holandês Arnold J. (Nol) Brederoo (Schlosser 1978, 1980; 1982; Schlosser et Brederoo 1981, 1985).

Schlosser também excursionou com Dirk Jan van Vliet, Walter Rausch, Karl Heinz Preslté, Heinz Ruoff e Wolf-Rainer Abraham. $\mathrm{Na}$ década de oitenta, ele contribuiu para estudos de Notocactus na revista alemã "Internoto", especializada no gênero. Seus artigos sobre 


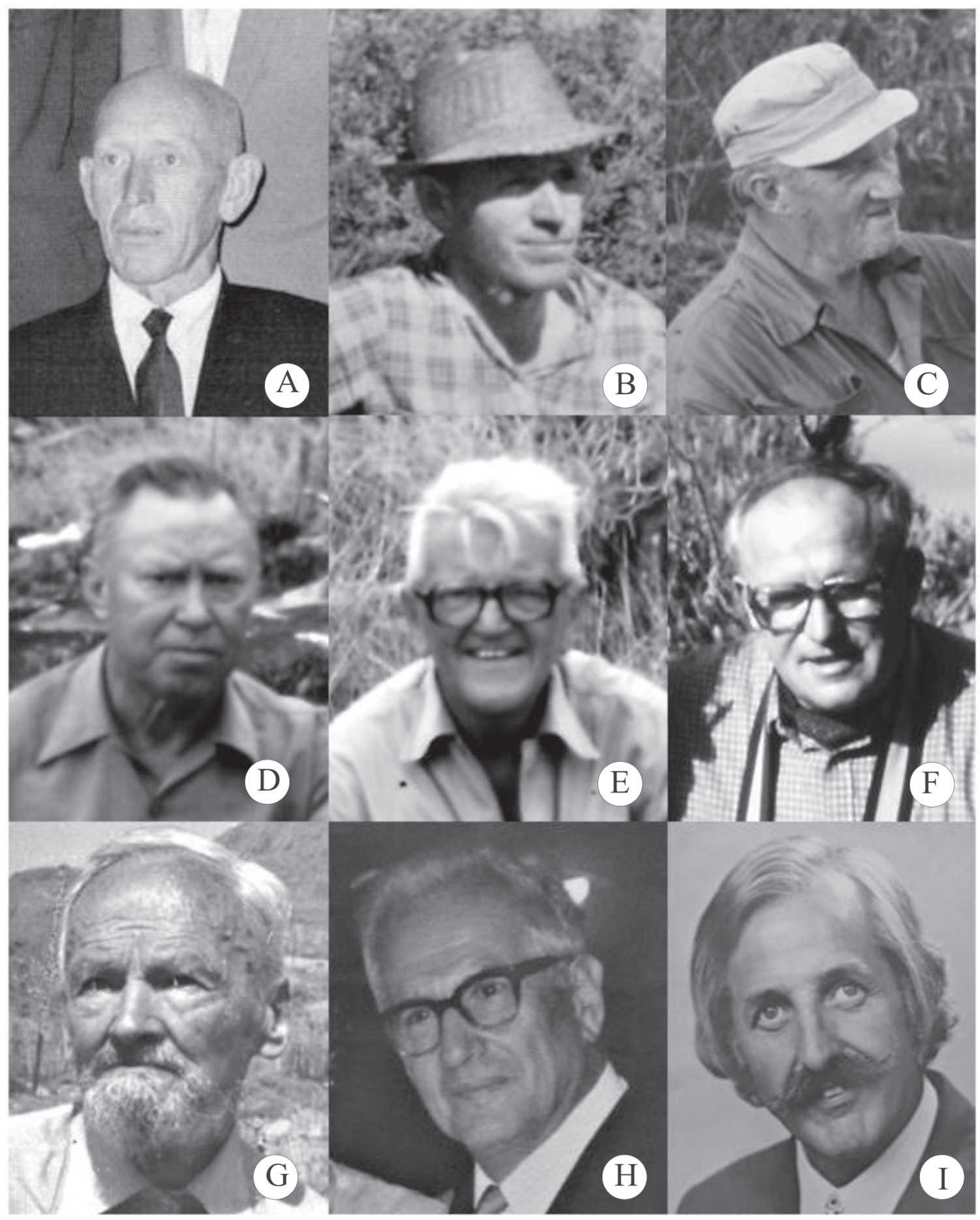

FIGURA 2: Ilustres cactólogos. A - Rudolfo Henrique Büneker. B - Rudi Werner Büneker. C - Eddie Waras. D - Leopoldo Horst. E - Albert Buining. F - Werner Uebelmann. G - Friedrich Ritter. H - Hugo Schlosser. I - Dirk Jan van Vliet. 
fenologia e distribuição geográfica demonstram grande conhecimento e excelente vivência de campo (Schlosser, 1985). Hugo também se preocupava em garantir sementes de boa qualidade, pureza e procedência. Sua coleção era rigorosamente tratada, com muito cuidado nas polinizações e propagação das plantas, restando a informar que parte desse material ainda perdura em coleções dispersas pela Europa (Abraham, 1984).

Em 1964, Duncan MacNair Porter ${ }^{17}$ estabeleceu o gênero Wigginsia em homenagem ao botânico americano Ira Loren Wiggins (18991987), com o objetivo de substituir o antigo gênero Malacocarpus (estabelecido por SalmDyck, em 1850), que era inválido pelo fato do nome já designar um gênero mais antigo de Zygophyllaceae (Porter, 1964).

Renomado botânico de Montevidéu, o professor Eduardo Marchesi de Leon (04-03-1943) transferiu Echinocactus erubescens (descrito por Osten) para o gênero Notocactus. Em 2102-1966, ele encontrou uma nova espécie do gênero no vale do Arroio Platón, a qual foi publicada em 1972 como Notocactus allosiphon; sobre a mesma, cumpre informar que sua distribuição restringe-se à fronteira do Uruguai com o Brasil (Marchesi, 1972, Gerloff, 2007).

Outra personalidade uruguaia de destaque é Miguel Angel Muriel, que colecionou no país de 1966 até sua morte, acontecida em 1993. A seu respeito, salienta-se a predileção pelos cactos, a descoberta de diversas populações no interior do país e seu renome como colecionador de plantas suculentas, cultivadas em sua propriedade no "Cerrito de la Vitoria", Montevidéu. Após sua morte, parte da coleção foi adquirida por Samuel Liberman e levada para o departamento de Maldonado, na costa leste do Uruguai (Burgueno, 1999).

${ }^{17}$ Nasceu em 1937, em Blacksburg (Inglaterra). Coletou espermatófitas para o "Natural History Museum" de 1960 a 1972, excursionando pela América do Sul, Panamá, Nicarágua, México e Estados Unidos.
Outro viveirista de destaque foi Dirk Jan van Vliet (15-09-1924), nascido em Nieuween, Holanda. Desde a infância ele conviveu com cactos, paixão herdada de seu pai, Frederik, gerente da estação local de correios (Theunissen, 2004). Consta que no escritório de Frederik havia uma pequena janela voltada para o sul, onde ele dispôs uma pequena caixa para o cultivo de cactos, entre os quais exemplares de Notocactus.

Ao concluir a escola primária, Dirk foi transferido para uma escola técnica, em Amsterdã, para estudar mecânica. Aos 16 anos, ele participou da Segunda Guerra Mundial, sendo duas vezes capturado pelos alemães e, posteriormente, deportado para a Alemanha. Conseguiu fugir em pleno inverno, saltando de um trem em movimento e, a pé, voltou para casa (Theunissen, 2014). Viveu em Woudbrugg na clandestinidade e se interessou por pintura, talento herdado de seus ancestrais. Após a Segunda Guerra Mundial, Dirk desenvolveu vários ofícios e formou-se maquinista de trem, profissão que desempenhou por muitos anos.

Em acidente, por volta de 1955, uma lasca de ferro penetrou em seu olho esquerdo. Mesmo com várias cirurgias, o fragmento não pode ser removido e, em conseqüência, ele passou a receber pensão vitalícia por invalidez (Theunissen, 2014), o que lhe disponibilizou tempo para dedicar-se aos cactos.

Dirk viveu em Scheveningen, onde tinha contato direto com renomados colecionadores da Holanda, como Cornelius Bommeljé, D. C. von Soldt, Jansen e Piet A. Roggen (Theunissen, 2004). Para melhor conhecimento das plantas, ele contatou o Dr. Boom, da Universidade Agrícola de Wageningen, para aperfeiçoar seus conhecimentos em Botânica. Com esse apoio, decidiu por visitar os cactos em seu habitat natural, mas, para isso, necessitava de companhia.

Em 1968, em sua primeira viagem à América do Sul, o seu parceiro foi Walter Rausch (Viena, 15-11-1928), cactófilo interessado em novidades. Com poucos recursos, os dois embarcaram em Veneza, rumo a Buenos Aires. De início, procuraram cactos pela Argentina e Bolí- 
via (Theunissen, 2004), partindo em seguida para o Uruguai. De Montevidéu seguiram para Piriápolis, onde foram acolhidos pelo cactófilo Hugo Schlosser, amigo Rausch, que muito os auxiliou na busca dos cactos (Theunissen, 2014). No interior do país - a pé, de bicicleta, motocicleta ou automóvel -, eles percorreram os departamentos de Rivera e Tacuarembó, onde encontram Notocactus vanvlietii (descrito por Rausch) e N. rauschii (descrito por van Vliet), bem como áreas fronteiriças com o Brasil.

Foi nessa viagem que Dirk conheceu Maria Eugenia Acosta (15-09-1939 - 08-11-1989), natural de Tacuarembó (Uruguai) e empregada doméstica de Hugo Schlosser (Theunissen, 2004). Depois de outras viagens, Dirk voltou sozinho para o Uruguai e, em 11-05-1973, casou-se com Eugênia em Montevidéu, decidindo radicar-se na América do Sul.

Após as primeiras viagens ao interior do Uruguai e Rio Grande do Sul, Dirk estabeleceu contato com o grande taxonomista Albert Buining, que também tinha grande interesse nos cactos austrais (Theunissen, 2014). Com o aprofundamento dos estudos, Dirk passou a descrever sozinho seus próprios achados. De 1968 até 1975, foram por ele descritos: Notocactus agnetae, $N$. blaauwianus, $N$. bommeljei, $N$. roseoluteus, $N$. schlosseri, $N$. soldtianus, $N$. eugeniae, $N$. veenianus, $N$. winklerie Wigginsia pulvinata (Schaeffer, 1979; Gerloff et al, 2004).

Depois de 1976, Dirk e Maria Eugenia transferiram-se para a cidade paulista de Holambra, colonizada por holandeses após o término da Segunda Guerra Mundial. Dirk retornou à Holanda com o objetivo de transferir com segurança a sua coleção de cactos de Scheveningen para o Brasil (Theunissen, 2004), sendo que parte do acervo de plantas foi vendido a Gehardt Köhres, um grande viveirista alemão, que ainda hoje mantêm algumas de suas plantas.

À procura de trabalho, ele foi convidado a construir um viveiro para cactos pelo Sr. Klaaus Schoenmaker, produtor importante em Holambra e que muito o ajudou em seu estabelecimento no país. Mais tarde, Dirk adquiriu o sítio Tunaflor, onde montou o seu próprio negócio de plantas ornamentais, com ajuda do enteado Ruben Acosta (Theunissen, 2004).

Após a morte da esposa, Dirk retomou, em 1991, as suas viagens em busca de cactos, acompanhando os amigos e cactófilos Gert Maly, Piet Rye e Gerardus Olsthroon. Mais tarde, descreveu Notocactus katharinae e Notocactus bregmannianus (Gerloff et al, 2004). Dirk ainda hoje mantêm sua coleção de cactos, alguns dos quais com mais de 50 anos em cultivo, e garante que pretende descrever algumas novidades, em breve.

Outra personalidade que percorreu a terra gaúcha e uruguaia foi o botânico tcheco Karel Kníze (07-10-1941), em fins dos anos sessenta e início da década de setenta.

Em agosto de 1975 foi editada a primeira obra dedicada, exclusivamente, ao gênero Notocactus. Em uma revisão do mesmo, foram incorporados gêneros até então distintos, como Brasilicactus, Eriocactus e Wigginsia (Mace, 1975).

Em 1978, Geoff Swales elevou Gymnocalycium buenekeri ao nível de espécie (Swales, 1978). Dois mais tarde, Gehardt Schäfer (19031998), botânico alemão e notável cultivador de cactos, publicou "Die Gattung Notocactus", obra que haverá de persistir como referência no gênero (Schäfer, 1980). No mesmo ano, o tcheco Radim Havlicek (16-02-1928-30-10-1998) publicou Notocactus mammulosus var. brasiliensis a partir de plantas importadas do Brasil, com localidade desconhecida (Havlicek, 1980).

\section{AGRADECIMENTOS}

Os autores agradecem a Ari Delmo Nilson, Hans Heinrich Brakemeier, Melita Brune Horst (in memorian), Rucart Egon Horst, Andreas Hofacker (Böblingen), Dirk Jan van Vliet, Helena da Silva van Vliet, Konrad Herm (Bad Herrenalb), Kurt Ingo Horst, Matheus Engster, Marino Gustavo Hamester, Rudi Werner Büneker, Wolf-Rainer Abraham (Hillerse), bem como ao professor Marcelo Antonio Rodrigues 
e ao Colégio Politécnico da UFSM, pelo decisivo apoio à realização desta pesquisa.

\section{REFERÊNCIAS BIBLIOGRÁFICAS}

ABRAHAM, W-R. Wir gratulieren Hugo Schlosser zum 80. Geburtstag. Kakteen und andere Sukkulenten, v. 35, n. 2, p. 32-33, 1984.

ABRAHAM, W-R. Reserva Biológica Rudolfo Henrique Büneker - das erst BiosphärenReservat für Kakteen in Brasilien entsteht in Rio Grande do Sul. Internoto, v. 17, n. 3, p. 88-90, 1996.

BRAUN, P. J. Leopoldo Horst - 65 Jahre! Kakteen und andere Sukkulenten, v. 34, n. 3, p. 65-66, 1983.

BERGESH, L.; BERSCH, N.A. Cactus Horst. Empreendedores do Vale do Taquari, Lajeado, $\mathrm{p}$. 61-74, 2012.

BREDEROO, A; THEUNISSEN, J. Notocactus linkii (Lehmann) Herter var. flavispinus Buining et Brederoo var. nov. Kakteen und andere Sukkulenten, v. 29, n. 2, p. 25-27, 1978.

BUINING, A.F.H. Parodia buenekeri. Succulenta, v. 41, n. 8, p. 99, 1962.

BUINING, A.F.H. Notocactus uebelmannianus spec. nov. Kakteen und andere Sukkulenten, v. 19, n. 9, p. 175-176, 1968.

BUINING, A.F.H. Notocactus rechensis Buining, spec. nov. Kakteen und andere Sukkulenten, v. 19, n. 2, p. 23-24, 1968.

BUINING, A.F.H. Gymnocalycium horstii spec. nov. Kakteen und andere Sukkulenten, v. 21, n. 5, p. 162-165, 1970.

BUINING, A.F.H. New Notocactus from Uruguay. Notocactus pseudoherteri Buining sp. nov. National Cactus \& Succulent Journal, v. 26, n. 1, p. 2-3, 1971.

BUINING, A.F.H; BREDEROO, A.J. Frailea fulviseta Buining et Brederoo spec. nov. Kakteen und andere Sukkulenten, v. 24, n. 8, p. 170-172, 1973.

BUINING, A.F.H; BREDEROO, A.J. Frailea aureinitens Buining et Brederoo spec. nov. Succulenta, v. 55, n. 4, p. 62-65, 1976.

BURGUENO, A. Die Sammlung des Miguel Muriel. Internoto, v. 20, n. 3, p.81-84, 1999.

BUXBAUM, F. Notocatctus subgen. Malacocarpus buiningii spec. nov. Kakteen und andere Sukkulenten, v. 19, n. 12, p. 229-231, 1968.
CARNEIRO, A.M; SINGER, R.F; RAMOS, R.A; NILSON, A.D. Cactos do Rio Grande do Sul. Porto Alegre: Fundação Zoobotânica do Rio Grande do Sul, 2016. 224 p.

CULLMANN, W. Brasilicactus graessneri K. Schum. var. albiseta Cullm. var. nov. Kakteen und andere Sukkulenten, v. 6, n. 1 p. 105, 1955.

EGGLI, U; SCHICK, M. M; LEUENBERGER, B. E. Cactaceae in South America: The Ritter collections. Englera, Berlim-Dahlem, v. 16, 1995, $646 \mathrm{p}$.

GERLOFF, N; NEDUCHAL, J. Taxonomische Neubearbeitung der Gattung Notocactus Fric. Internoto, v. 25, n. 2, 2004, 128 p.

GERLOFF, N. Notocactus allosiphon Marchesi. Internoto, v. 28, n.3, p. 51-63, 2007.

KALMBACHER, G. Trip to Brazil. Journal of bromeliad Society, v. 21, n. 5, p.100-106, 1971.

HAAGE, W. Parodia brevihamata W. Haage. Descriptiones Cactacearum Novarum, v. 1, p. 31, 1956.

HAVLICEK, R. Notocactus mammulosus (Lem.) Berg. var. brasiliensis Havlicek. var. nov. Kaktusy, v. 16, n. 1, p. 5-7, 1980.

HERM, K. Zum Tode von Selmar Hugo Schlosser. Internoto, v. 8, n.2, p. 54-55, 1987.

HERM, K. Die Pflanzengruppe um Notocactus horstii. Internoto, v. 11, n. 2-3, p. 64-67, 1990.

HERM, K.; HOFACKER, A.; CHARLES, G; VAN HEEK, W; BOHLE, B; STECKER, W; HEIMEN, G. Kakteen in Brasilien. Hügelsheim, 2000. $176 \mathrm{p}$.

MARCHESI, E. Notocactus allosiphon spec. nov. Boletin de la Sociedad Argentina de Botánica, n. 3, p. 246-248, 1972.

MÜLLER, W. Friedrich Ritter. Kakteen und andere Sukkulenten, v. 40, n. 2, p. 137, 1989.

PONTES, R.C.; MARCHIORI, J.N.C.; WITECK NETO, L. Notas históricas sobre a família Cactaceae no Rio Grande do Sul (Brasil) e Uruguai. I - Período Clássico (1818-1950): viajantes naturalistas e botânicos europeus. Balduinia, Santa Maria, n. 56, p. 1-11, 2017.

PORTER, D. M. A new name for Malacocarpus. Taxon, n. 13, p. 201-211, 1964.

RITTER, F. Uber mein Leben und meine Forschungsund Sammeireisen. Kakteen und andere Sukkulenten, v. 15, n. 11, p. 224-226, 1964.

RITTER, F. Notocactus horstii Ritter spec. nov. Succulenta, v. 45, n. 1, p. 3-4, 1966. 
RITTER, F. Eriocactus magnificus Ritter spec. nov. Succulenta, v. 45, n. 4, p. 50-53, 1966.

RITTER, F. Eriocactus claviceps Ritter spec. nov. Succulenta, v. 45, n. 8, p. 115-116, 1966.

RITTER, F. Nieuwe cactussen uit Zuid-Amerika I. Succulenta, v. 49, n. 7, p. 108-109, 1970.

RITTER, F. 40 Jahre Abenteuerleben und die wilde Weisheit. Spangenberg: Friedrich Ritter Verlag, 1977. 320 p.

RITTER, F. Kakteen in Südamerika. Band 1. Brasilien/Uruguay/Paraguay. Spangenberg: Friedrich Ritter Selbstverlag, 1979. 374 p.

RITTER, F. Ein neuer "Eriocactus". Bradea - Boletim do Herbário Bradeanum, Rio de Janeiro, v. 1, p. 352-354, 1973.

RITTER, F. Kakteen in Südamerika. Band 4. Peru. Spangenberg: Friedrich Ritter Selbstverlag, 1981. 453 p.

SCHÄFER, G. Die Gattung Notokakteen. Kakteen/ Sukkulenten, n. 14, 1-4, 1980. 124 p.

SCHLOSSER, H.S. Notocactus (Neonotocactus) roseiflorus Schlosser et Brederoo spec. nov. Kakteen und andere Sukkulenten, v. 29, n. 12, p. 237-277, 1978.

SCHLOSSER, H.S. Notocactus paulus Schlosser et Brederoo spec. nov. Kakteen und andere Sukkulenten, v. 31, n. 4, p. 114-116, 1980.

SCHLOSSER, H.S. Notocactus ferrugineus
Schlosser spec. nov. Internoto, v. 3, n. 2, p. 2326, 1982.

SCHLOSSER, H. Die Phytogeographische Provinz Uruguay in Sinne der Kakteen. Internoto. v. 6 , n. 3, p. 71-74, 1985.

SCHLOSSER, H.S. \& BREDEROO, A.J. Notocactus megalanthus Schlosser et Brederoo. Kakteen und andere Sukkulenten, v. 32, n. 7, p. 154-157, 1981.

SCHLOSSER, H.S.; BREDEROO, A.J. Ein neuer Notocactus aus Uruguay. Kakteen und andere Sukkulenten, v. 36, n. 9, p. 186-189, 1985.

SWALES, G. J. Gymnocalcyium buenekeri spec. nov. The Cactus and Suculent Journal of Great Britain, v. 40, n. 4, p. 87-100, 1978.

THEUNISSEN, S. Dirk van Vliet, 80 Jahre jung. Internoto, v. 25, n. 4, p. 141-146, 2004.

THEUNISSEN, J. Dirk van Vliet: 90 Jahre jung. Internoto. v. 34, n. 4, p. 86-94, 2014.

MACE, T. Notocactus: a review of the genus, incorporating Brasilicactus, Eriocactus and Wigginsia. National Cactus Succulent Society, $1975.85 \mathrm{p}$.

WITTAU, H.-J. Geburtstagsgrüsse an Friedrich Ritter. Kakteen und andere Sukkulenten. v. 33, n. 5, p. 107, 1982.

UEBELMANN, W. J. Feldnummernliste Horst \& Uebelmann. Selbstverlag Werner Uebelmann, 1996. 204 p. 